\title{
A RELATION BETWEEN MOMENT GENERATING FUNCTIONS AND CONVERGENCE RATES IN THE LAW OF LARGE NUMBERS
}

\author{
BY D. L. HANSON ${ }^{1}$
}

Communicated by M. Loève, July 20, 1966

Let $X_{N}$ for $N=0, \pm 1, \cdots$ be independent random variables with finite first absolute moments; let $A_{N}=\left\{a_{N, k}: k=0, \pm 1, \cdots\right\}$; let $\left\|A_{N}\right\|_{\infty}=\sup _{k}\left|a_{N, k}\right|$ and $\left\|A_{N}\right\|_{p}=\left[\sum_{k}\left|a_{N, k}\right|^{p}\right]^{1 / p}$ for $1 \leqq p<\infty$; let $S_{N}=\sum_{k} a_{N, k}\left(X_{k}-E X_{k}\right)$; and let $p$ and $q$ be numbers in $[1, \infty]$ satisfying $1 / p+1 / q=1$.

THEOREM. Suppose there exist positive constants $M, \gamma$, and $1 \leqq p \leqq 2$ such that for $0<x<\infty$ and all values of $k$

$$
P\left\{\left|X_{k}-E X_{k}\right| \geqq x\right\} \leqq \int_{x}^{\infty} M \exp \left(-\gamma t^{p}\right) d t .
$$

Suppose $\left\|A_{N}\right\|_{2}$ and $\left\|A_{N}\right\|_{Q}$ are finite for all $N$. Then

$$
T_{N}=\lim _{\alpha \rightarrow-\infty ; \beta \rightarrow \infty} \sum_{k=\alpha}^{\beta} a_{N, k}\left(X_{k}-E X_{k}\right)
$$

exists as an almost sure limit for each $N$ and there exist positive constants $C_{1}$ and $C_{2}$ such that for every $\epsilon>0$

$$
P\left\{T_{N} \geqq \epsilon\right\} \leqq \exp \left[-\min \left\{C_{1}\left(\frac{\epsilon}{\left\|A_{N}\right\|_{2}}\right)^{2}, C_{2}\left(\frac{\epsilon}{\left\|A_{N}\right\|_{q}}\right)^{p}\right\}\right] .
$$

The constants $C_{1}$ and $C_{2}$ which are obtained depend only on $M, \gamma$, and $p$. They do not depend in any other way on the distribution of the $X_{k}^{\prime}$ 's and they do not depend on the coefficient sequences $A_{N}$.

When $p=1$ the condition (1) is equivalent to the existence of constants $T>0$ and $C>0$ such that $E \exp \left(t X_{k}\right) \leqq \exp \left(C t^{2}\right)$ for all $k$ and all $|t|<T$; when $1<p \leqq 2$ it is equivalent to the existence of a constant $C>0$ such that $E \exp \left(t X_{k}\right) \leqq \exp \left[C\left(t^{2}+|t|^{q}\right)\right]$ for all $k$ and $t$.

$$
\text { If } \begin{aligned}
p=1 \text { and } a_{N, k} & =1 / N & & \text { for } k=1, \cdots, N, \\
& =0 & & \text { otherwise, }
\end{aligned}
$$

\footnotetext{
${ }^{1}$ Research partially supported by the Air Force Office of Scientific Research, Office of Aerospace Research, United States Air Force, under AFOSR Grant Nr AF. AFOSR-746-65.
} 
then this theorem reduces to the well known result (see [1] and [2]) giving exponential convergence rates in the law of large numbers; that is, the theorem guarantees $0 \leqq \rho_{\epsilon}<1$ such that $P\left\{T_{N} \geqq \epsilon\right\} \leqq\left(\rho_{\epsilon}\right)^{N}$ for all $N$.

If $p=1$ and $\left\|A_{N}\right\|_{1} \leqq M<\infty$ for all $N$, then since $\left\|A_{N}\right\|_{2}^{2} \leqq\left\|A_{N}\right\|_{1}$ $\times\left\|A_{N}\right\|_{\infty}$ we see that there exists $0 \leqq \rho_{\varepsilon}<1$ such that $P\left\{T_{N} \geqq \epsilon\right\}$

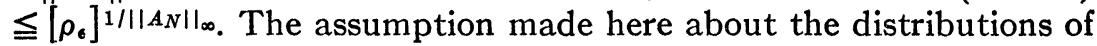
the $X_{k}$ 's is equivalent to that made in (1) of Theorem 1 of [3]. Thus we obtain Theorem 1 of [3] as a corollary to the theorem given above. We actually obtain a stronger result than Theorem 1 of [3] since it is not necessary for $\left\|A_{N}\right\|_{1}$ to even be finite for our theorem to hold.

If $p=2$, then $\left\|A_{N}\right\|_{2}=\left\|A_{N}\right\|_{q}$ and we obtain $P\left\{T_{N} \geqq \epsilon\right\} \leqq\left[\rho_{\epsilon}\right]^{1 /\left\|A_{N}\right\|_{2}^{2}}$ for some $0 \leqq \rho_{e}<1$. This is essentially Chow's Lemma 2 in [4]. We can obtain generalized versions of his Theorems 1 and 2 from our theorem.

Note that no improvement can be obtained by taking $p>2$, and in fact not even by assuming a uniform bound on the $X_{k}$ 's. The Central Limit Theorem seems to provide a bound on the rate of convergence obtained in this theorem.

A continuous case analogue similar to the theorem of [5] and proofs will be published elsewhere.

\section{REFERENCES}

1. H. Cramér, Sur un nouveau théorème-limite de la theorie des probabilités, Actualités Sci. Indust., No. 736, Paris, 1938.

2. Herman Chernoff, $A$ measure of asymptotic efficiency for tests of a hypothesis based on the sum of observations, Ann. Math. Statist. 23 (1952), 493-507.

3. D. L. Hanson and L. H. Koopmans, On the convergence rate of the law of large numbers for linear combinations of independent random variables, Ann. Math. Statist. 36 (1965), 559-564.

4. Y. S. Chow, Some convergence theorems for independent random variables, Tech. Report No. 63, Purdue University, Lafayette, Indiana, 1966.

5. D. L. Hanson and L. H. Koopmans, $A$ probability bound for integrals with respect to stochastic processes with independent increments, Proc. Amer. Math. Soc. 16 (1965), 1173-1177.

UNIVERSITY OF MisSOURI 